Research article

\title{
Biophysical probing of Spartina maritima photo-system II changes during prolonged tidal submersion periods
}

\author{
B. Duarte ${ }^{\mathrm{a}, *}$, D. Santos ${ }^{\mathrm{a}}$, J.C. Marques ${ }^{\mathrm{b}}$, I. Caçador ${ }^{\mathrm{a}}$ \\ ${ }^{a}$ Centre of Oceanography, Faculty of Sciences, University of Lisbon (CO), Campo Grande, 1749-016 Lisbon, Portugal \\ ${ }^{\mathrm{b}}$ Institute of Marine Research, Marine and Environment Research Centre (IMAR-CMA), c/o Department of Zoology, Faculty of Sciences and Technology, \\ University of Coimbra, 3000 Coimbra, Portugal
}

\section{A R T I C L E I N F O}

\section{Article history:}

Received 21 December 2013

Accepted 30 January 2014

Available online 6 February 2014

\section{Keywords:}

Sea level rise

Underwater photosynthesis

OJIP transients

PSII photochemistry

Biophysical probing of photosynthesis

\begin{abstract}
A B S T R A C T
Submergence is one of the major constrains affecting wetland plants, with inevitable impacts on their physiology and productivity. Global warming as a driving force of sea level rise, tend to increase the submersion periods duration. Photosynthesis biophysical probing arise as an important tool to understand the energetics underlying plant feedback to these constrains. As in previous studies with Spartina maritima, there was no inhibition of photosynthetic activity in submerged individuals. Comparing both donor and acceptor sides of the PSII, the first was more severely affected during submersion, driven by the inactivation of the OEC with consequent impairment of the ETC. Although this apparent damage in the PSII donor side, the electron transport per active reaction centre was not substantially affected, indicating that this reduction in the electron flow is accompanied by a proportional increase in the number of active reaction centres. These conditions lead to the accumulation of excessive reducing power, source of damaging ROS, counteracted by efficient energy dissipation processes and anti-oxidant enzymatic defences. This way, S. maritima appears as a well-adapted species with an evident photochemical plasticity towards submersion, allowing it to maintain its photosynthetic activity even during prolonged submersion periods.
\end{abstract}

(ㄷ) 2014 Elsevier Masson SAS. All rights reserved.

\section{Introduction}

Although salt marshes are widely recognized as one of the major contributors for estuarine primary productivity (Caçador et al., 2009), these ecosystems present several environmental constrains that affect the species distribution and zonation (Caçador et al., 2007). Tidal flooding is one of the most important stressors shaping these landscapes, while submerging the halophytic vegetation inhabiting salt marshes (Hubbard, 1969; Armstrong et al., 1985; Bertness, 1991; Winkel et al., 2011). Halophytes are normally defined as "plants that complete their life cycle in a salt concentration of at least $200 \mathrm{mM} \mathrm{NaCl}$ under conditions similar to those that might be encountered in the terrestrial environment" (Flowers and Colmer, 2008). Although halophytes can be found in saline deserts, most of the world halophyte populations inhabit coastal areas (like salt marshes and mangroves) prone to tidal flooding (Colmer and Flowers, 2008). Flooding has several consequences not only on halophytes, but also in their rhizosediment

\footnotetext{
* Corresponding author. Tel.: +351 217500 000x20305.

E-mail address: baduarte@fc.ul.pt (B. Duarte).
}

(Burdick and Mendelssohn, 1987). With flooding, sediment becomes anoxic with a lower redox potential (Duarte et al., 2009). In this case plant survival becomes dependent upon the establishment of an oxygen flow from the atmosphere into the aerial organs and finally pumped into the rhizosphere, supporting root aerobic respiration and enhancing toxic forms detoxification (Burdick and Mendelssohn, 1987; Armstrong, 1979). Several halophytes developed root aerenchyma in order to increase root aeration (Sifton, 1945; Iversen, 1949; Armstrong, 1972). Other types of mechanisms of submergence tolerance include shoot elongation, a quiescence response to conserve energy until the water drawbacks, adventitious root formation and traits conferring the ability to preform underwater photosynthesis (Winkel et al., 2011; BaileySerres and Voesenek, 2008; Colmer and Voesenek, 2009). At the leaf level several constrains arise. Not only the $\mathrm{CO}_{2}$ gas slow diffusion in the aquatic environment limits its uptake by leaves (Smith and Walker, 1980), but also the decreased light availability, due to light attenuation along the water column (Pedersen and Colmer, 2006), impairs photosynthesis (Sand-Jensen, 1989). This photosynthetic impairment due to low $\mathrm{CO}_{2}$ or low light, leads to a depletion in the $\mathrm{O}_{2}$ production, with less $\mathrm{O}_{2}$ to be diffused from the leaves to the roots, and thus increasing the anoxia driven stress at 
the sediment level (Colmer and Flowers, 2008). Moreover, plant feedback to flooding events will be also function of the duration and water column depth, and of course, plant genotype (Setter and Waters, 2003; Voesenek et al., 2004). Due to obvious geographical constrains, the species inhabiting the lower parts of coastal marshes are more exposed both to normal tidal flooding, but also to prolonged flooding events.

Spartina maritima (L.) Loisel (Poaceae), has a very wide distribution in the northern hemisphere, native to the coasts of western and northern Europe and western Africa, with also a disjunct population on the Atlantic coasts of Namibia and South Africa (Marchant and Goodman, 1969). It is typically considered as a pioneer species (Caçador et al., 2007) inhabiting the mudflats and lower marshes. Its sediment is often waterlogged and undergo tidal flooding twice per day during, with an average and maximum flooding duration of $2 \mathrm{~h}$ (during spring tides) and 1-1.5 h (during normal tides) respectively.

Considering the present climatic change projections this subject acquires an even greater importance. Many coastal marshes are prone to storm surges and river flooding, driven by extreme climate events, that in nowadays are becoming more frequent (Egan and Ungar, 2000; Pedersen and Colmer, 2006). Also the projections of sea level rise point out to increased inundations of coastal marshes (Reed, 2002). All these climatic events will increase the frequency and duration of tidal flooding especially on the lower marshes.

In the present study, we examine the photochemical and biochemical adaptations of $S$. maritima to high duration submersion periods, and its photosynthetic ability and underlying photochemical mechanisms during prolonged submersion periods. This will allow understanding the plasticity and adaptation capacity of this species, in a for e.g. climate change scenarios of prolonged tidal flooding due to sea level rise.

\section{Material and methods}

\subsection{Plant harvest and mesocosmos setup}

Intact turfs of $S$. maritima were collected at in the summer, one day before the experiments start, at Tagus estuary (Alcochete, $\left.38^{\circ} 45^{\prime} 38.78^{\prime \prime} \mathrm{N}, 8^{\circ} 56^{\prime} 7.37^{\prime \prime} \mathrm{W}\right)$. The intact turfs were transported to the laboratory of Marine Botany of the Centre of Oceanography, in air exposed aquariums $(60 \times 60 \times 60 \mathrm{~cm})$ and placed in a normal photoperiod $(16 \mathrm{~h} / 8 \mathrm{~h}$ light/dark $)$ at $20^{\circ} \mathrm{C}$, until the beginning of the experiments. To avoid dryness, sediment was supplemented with $1 / 4$ Hoagland solution with the salinity adjusted to 20 PSU (estuarine salinity) to maintain moister conditions from the field.

Two aquariums were prepared by filling the bottom with S. maritima transplants in order to simulate the normal displacement within a pure stand of this species. One of the aquariums was filled with artificial estuarine water supplemented with $1 / 4$ Hoagland solution nutrients. The fill up of the aquarium was done slowly (10 min) and gently to avoid sediment resuspension and water column turbidity. At the end the individuals were completely submersed. In the other aquarium the individuals remained in normal air-exposed conditions. Both aquariums were illuminated with a fluorescent light with a PAR at the leaf level of $400 \mu \mathrm{mol}$ photons $\mathrm{m}^{-2} \mathrm{~s}^{-1}$ in the air exposed aquarium and of $370 \mu \mathrm{mol}$ photons $\mathrm{m}^{-2} \mathrm{~s}^{-1}$. Both irradiances are within the optimal and maximum productivity range for this species in Mediterranean marshes (Duarte et al., 2013a). Leaf samples (for biochemical analysis) were harvest at the beginning of the experiment $\left(T_{0}\right)$ and every $30 \mathrm{~min}$ and flash frozen in liquid- $\mathrm{N}_{2}$. Since each turf included several individuals these were considered as pseudo-replicates in each aquarium. In field conditions this species undergoes flooding periods of typically $2 \mathrm{~h}$ (Serôdio and Catarino, 2000). In order to evaluate its tolerance to increased submersion periods the submersion experiments were taken out during $3 \mathrm{~h}$.

\subsection{PAM fluorometry}

All chlorophyll fluorescent measurements (Table 1) were also performed every $30 \mathrm{~min}$. Modulated chlorophyll fluorescence measurements were made in attached leaves in field with a FluoroPen FP100 PAM (Photo System Instruments, Czech Republic). For all measurements were used leaves from the light incubations. All the measurements in the dark-adapted state were made after darkening of the leaves for at least $30 \mathrm{~min}$. The minimal fluorescence $\left(\mathrm{F}_{0}\right)$ in dark-adapted state was measured by the measuring modulated light, which was sufficiently low $\left(<0.1 \mu \mathrm{mol} \mathrm{m}{ }^{-2} \mathrm{~s}^{-1}\right)$ not to induce any significant variation in fluorescence. The maximal fluorescence level $\left(F_{M}\right)$ in dark-adapted state was measured by a $0.8 \mathrm{~s}$ saturating pulse at $8000 \mu \mathrm{mol} \mathrm{m} \mathrm{m}^{-2} \mathrm{~s}^{-1}$. The maximum photochemical efficiency was assessed as $\left(F_{M}-F_{0}\right) / F_{M}$. The same parameters were also measured in light -adapted leaves, being $\mathrm{F}_{0}$ the minimum fluorescence, $\mathrm{F}_{\mathrm{M}}$ the maximum fluorescence and the operational photochemical efficiency. Rapid light curves (RLC)

Table 1

Summary of Fluorometric analysis parameters and their description.

\begin{tabular}{|c|c|}
\hline \multicolumn{2}{|l|}{ Photosystem II Efficiency } \\
\hline$F_{0}$ and $F_{0}$ & $\begin{array}{l}\text { Basal Fluorescence under weak actinic light } \\
\text { in light and dark adapted leaves. }\end{array}$ \\
\hline$F_{M}$ and $F_{M}$ & $\begin{array}{l}\text { Maximum Fluorescence measured after a } \\
\text { saturating pulse in light and dark adapted } \\
\text { leaves. }\end{array}$ \\
\hline$F_{\mathrm{v}}$ and $F_{v}$ & $\begin{array}{l}\text { Variable fluorescence light }\left(\mathrm{F}_{\mathrm{M}}^{\prime}-\mathrm{F}_{0}^{\prime}\right) \text { and } \\
\text { dark }\left(F_{M}-F_{0}\right) \text { adapted leaves. }\end{array}$ \\
\hline $\begin{array}{l}\text { PSII Operational and } \\
\text { Maximum Quantum }\end{array}$ & $\begin{array}{l}\text { Light and dark adapted Quantum yield of } \\
\text { primary photochemistry, equal to the }\end{array}$ \\
\hline Yield & $\begin{array}{l}\text { efficiency by which an absorbed photon } \\
\text { trapped by the PSII reaction centre will } \\
\text { result in reduction of } Q_{A} \text { to } Q^{-} A \text {. }\end{array}$ \\
\hline NPQ & $\mathrm{NPQ}=\left(F_{M}-F_{M}^{\prime}\right) / F_{M}$ \\
\hline \multicolumn{2}{|l|}{ Rapid Light Curves (RLCs) } \\
\hline rETR & $\begin{array}{l}\text { Relative electron transport rate at each } \\
\text { light intensity }(\mathrm{rETR}=\mathrm{QY} \times \mathrm{PAR} \times 0.5) \text {. }\end{array}$ \\
\hline$\alpha$ & $\begin{array}{l}\text { Photosynthetic efficiency, obtained from } \\
\text { the initial slope of the RLC. }\end{array}$ \\
\hline \multicolumn{2}{|l|}{ OJIP derived parameters } \\
\hline$\psi_{\mathrm{P} 0}$ & Maximum Yield of Primary Photochemistry. \\
\hline$\psi_{\mathrm{EO}}$ & $\begin{array}{l}\text { Probability that an absorbed photon will } \\
\text { move an electron into the ETC. }\end{array}$ \\
\hline$\psi_{\mathrm{D} 0}$ & $\begin{array}{l}\text { Quantum yield of the non-photochemical } \\
\text { reactions. }\end{array}$ \\
\hline$\varphi_{0}$ & $\begin{array}{l}\text { Probability of a PSII trapped electron to } \\
\text { be transported from } Q_{A} \text { to } Q_{B} \text {. }\end{array}$ \\
\hline Area & $\begin{array}{l}\text { Area above the fluorescence Kautsky } \\
\text { curve. Directly related to the size of the } \\
\text { acceptor pool of the PSII, including quinones } \\
\text { and plastoquinone. }\end{array}$ \\
\hline$P_{G}$ & $\begin{array}{l}\text { The Grouping Probability is a direct } \\
\text { measure of the connectivity between the } \\
\text { two PSII units (Strasser and Stirbet, 2001). }\end{array}$ \\
\hline $\mathrm{ABS} / \mathrm{RC}$ & Absorbed energy flux $\left(\mathrm{F}_{0}\right)$. \\
\hline $\mathrm{TR}_{0} / \mathrm{RC}$ & Trapped energy flux $\left(\mathrm{ABS} / \mathrm{RC} \times \psi_{\mathrm{PO}}\right)$. \\
\hline $\mathrm{ET}_{0} / \mathrm{RC}$ & $\begin{array}{l}\text { Electron transport energy flux }\left(\psi_{\mathrm{PO}} \times \varphi_{0} \times\right. \\
\mathrm{ABS} / \mathrm{RC}) \text {. }\end{array}$ \\
\hline $\mathrm{DI}_{0} / \mathrm{RC}$ & Dissipated energy flux (ABS/RC $\left.-\mathrm{TR}_{0} / \mathrm{RC}\right)$. \\
\hline $\begin{array}{l}\text { Diving Force for } \\
\text { Photosynthesis (DF ABS) }\end{array}$ & $\left.\mathrm{DF} A B S=\mathrm{DF} R C+\mathrm{DF} \psi_{\mathrm{P} 0}+\mathrm{DF} \varphi\right)$ \\
\hline $\begin{array}{l}\text { Driving Force for Trapping } \\
\left.\text { electronic energy (DF } \psi_{\mathrm{PO}}\right)\end{array}$ & $\mathrm{DF} \psi_{\mathrm{PO}}=\log \left(\psi_{\mathrm{PO}} /\left(1-\psi_{\mathrm{PO}}\right)\right.$ \\
\hline $\begin{array}{l}\text { Driving Force for Electron } \\
\text { Transport }(\mathrm{DF} \varphi)\end{array}$ & $\mathrm{DF} \varphi=\log \left(\varphi_{0} /\left(1-\varphi_{0}\right)\right.$ \\
\hline $\begin{array}{l}\text { Driving Force for Energy } \\
\text { Absorption (DF RC) }\end{array}$ & $\mathrm{DF} \mathrm{RC}=\log (\mathrm{RC} / \mathrm{ABS})$ \\
\hline
\end{tabular}


measurements, in dark-adapted leaves, were attained using the pre-programed LC1 protocol of the FluoroPen, consisting in a sequence of pulses from 0 to $500 \mu \mathrm{mol} \mathrm{m} \mathrm{m}^{-2} \mathrm{~s}^{-1}$. During this protocol the $F_{0}$ and $F_{M}$ as well as the maximum photochemical efficiency were measured. Each $\Phi_{\text {PSII }}$ measurement was used to calculate the electron transport rate (ETR) through photosystem II using the following equation: ETR $=\Phi_{\text {PSII }} \times$ PAR $\times 0.5$, where PAR is the actinic photosynthetically active radiation generated by the FluoroPen and 0.5 assumes that the photons absorbed are equally partitioned between PSII and PSI (Genty et al., 1989). Without knowledge of the actual amount of light being absorbed, fluorescence measurements can only be used as an approximation for electron transport (Beer et al., 1998a, 1998b; Runcie and Durako, 2004). Rapid light curves (RLC) were generated from the calculated ETRs and the irradiances applied during the rapid light curve steps. Each RLC was fitted to a double exponential decay function in order to quantify the characteristic parameters, alpha and ETR $_{\max }$ (Platt et al., 1980). The initial slope of the $\operatorname{RLC}(\alpha)$ is a measure of the light harvesting efficiency of photosynthesis and the asymptote of the curve, the maximum rate of photosynthesis $\left(\mathrm{ETR}_{\max }\right)$, is a measure of the capacity of the photosystems to utilize the absorbed light energy (Marshall et al., 2000). The onset of light saturation $\left(E_{k}\right)$ was calculated as the ratio between $\mathrm{ETR}_{\max }$ and $\alpha$. Excitation light of $650 \mathrm{~nm}$ (peak wavelength) from array of three light and emitting diodes is focused on the surface of the leaf to provide a homogenous illumination. Light intensity reaching the leaf was $3000 \mu \mathrm{mol} \mathrm{m} \mathrm{m}^{-2} \mathrm{~s}^{-1}$, which was sufficient to generate maximal fluorescence in all individuals. The fluorescence signal is received by the sensor head during recording and is digitized in the control unit using a fast digital converter. The OJIP transient (or Kautsky curves) depicts the rate of reduction kinetics of various components of PS II. When dark-adapted leaf is illuminated with the saturating light intensity of $3500 \mu \mathrm{mol} \mathrm{m} \mathrm{m}^{-2} \mathrm{~s}^{-1}$ then it exhibits a polyphasic rise in fluorescence (OJIP). Each letter reflects distinct inflection in the induction curve. The level $\mathrm{O}$ represents all the open reaction centres at the onset of illumination with no reduction of $Q_{A}$ (fluorescence intensity lasts for $10 \mathrm{~ms}$ ). The rise of transient from $\mathrm{O}$ to $\mathrm{J}$ indicates the net photochemical reduction of $Q_{A}$ (the stable primary electron acceptor of PS II) to $Q_{A}^{-}$(lasts for $2 \mathrm{~ms}$ ). The phase from $\mathrm{J}$ to I was due to all reduced states of closed RCs such as $Q_{A}^{-} Q_{\bar{B}}^{-}, Q_{A} Q_{B}^{2-}$ and $Q_{A}^{-} Q_{B} \mathrm{H}_{2}$ (lasts for $2-30 \mathrm{~ms}$ ). The level $\mathrm{P}(300 \mathrm{~ms})$ coincides with maximum concentration of $Q_{A}^{-} Q_{B}^{2}$ with plastoquinol pool maximally reduced. The phase $\mathrm{P}$ also reflects a balance between light incident at the PS II side and the rate of utilization of the chemical (potential) energy and the rate of heat dissipation (Zhu et al., 2005). From this analysis several photochemical parameters were attained (Table 1).

\subsection{Oxidative stress biomarkers}

All enzymatic analyses were performed at $4{ }^{\circ} \mathrm{C}$. Briefly, a proportion of $500 \mathrm{mg}$ of fresh leaves for $8 \mathrm{ml}$ of $50 \mathrm{mM}$ sodium phosphate buffer ( $\mathrm{pH}$ 7.6) with $0.1 \mathrm{mM}$ Na-EDTA, was used for the extraction procedure. The homogenate was centrifuged at $8923 \mathrm{rpm}$ for $20 \mathrm{~min}$, at $4{ }^{\circ} \mathrm{C}$, and the supernatant was used for the enzymatic assays. Catalase (CAT) activity was measured according to the method of Teranishi et al. (1974), by monitoring the consumption of $\mathrm{H}_{2} \mathrm{O}_{2}$, and consequent decrease in absorbance at $240 \mathrm{~nm}$. $\left(\varepsilon=39.4 \mathrm{mM}^{-1} \mathrm{~cm}^{-1}\right)$. The reaction mixture contained $50 \mathrm{mM}$ of sodium phosphate buffer ( $\mathrm{pH} 7.6), 0.1 \mathrm{mM}$ of Na-EDTA, and $100 \mathrm{mM}$ of $\mathrm{H}_{2} \mathrm{O}_{2}$. The reaction was initiated with the addition of the extract. Ascorbate peroxidase was assayed according to Tiryakioglu et al. (2006). The reaction mixture contained $50 \mathrm{mM}$ of sodium phosphate buffer ( $\mathrm{pH} 7.0$ ), $12 \mathrm{mM}$ of $\mathrm{H}_{2} \mathrm{O}_{2}, 0.25 \mathrm{mM} \mathrm{L}-$ ascorbate. The reaction was initiated with the addition of $100 \mu \mathrm{L}$ of enzyme extract. The activity was recorded as the decrease in absorbance at $290 \mathrm{~nm}$ and the amount of ascorbate oxidized was calculated from the molar extinction coefficient of $2.8 \mathrm{mM}^{-1} \mathrm{~cm}^{-1}$. Guaiacol peroxidase was measured by the method of Bergmeyer et al. (1974) with a reaction mixture consisting of $50 \mathrm{mM}$ of sodium phosphate buffer ( $\mathrm{pH} 7.0$ ), $2 \mathrm{mM}$ of $\mathrm{H}_{2} \mathrm{O}_{2}$, and $20 \mathrm{mM}$ of guaiacol. The reaction was initiated with the addition of $100 \mu \mathrm{L}$ of enzyme extract. The enzymatic activity was measured by monitoring the increase in absorbance at $470 \mathrm{~nm}\left(\varepsilon=26.6 \mathrm{mM}^{-1} \mathrm{~cm}^{-1}\right)$. Superoxide dismutase activity was assayed according to Marklund and Marklund (1974) by monitoring the reduction of pyrogallol at $325 \mathrm{~nm}$. The reaction mixture contained $50 \mathrm{mM}$ of sodium phosphate buffer ( $\mathrm{pH} 7.6$ ), $0.1 \mathrm{mM}$ of Na-EDTA, $3 \mathrm{mM}$ of pyrogallol, Mili$\mathrm{Q}$ water. The reaction was started with the addition of $10 \mu \mathrm{L}$ of enzyme extract. Control assays were done in the absence of substrate in order to evaluate the auto-oxidation of the substrates. Protein content in the extracts was determined according to Bradford (1976).

\subsection{Statistical analysis}

Due to the lack of normality and homogeneity, the statistical analysis of the data was based in non-parametric tests. In order to compare the effects of the two tested environments (air and underwater), the Krustal-Wallis test was performed using Statistica Software (Statasoft).

\section{Results}

\subsection{PSII quantum yields}

Overlooking the dark-adapted leaves variable fluorescence and quantum yields (Figs. 1B and D) no difference could be detected, neither along the time course nor between the air exposed and the submerged individuals. On the other hand, if the operational yields and light-adapted variable fluorescence are observed (Figs. 1A and C), notorious differences arise. The variable fluorescence in the light-adapted leaves of the air exposed individuals maintained its value almost constant along the time course. As for the submerged leaves, this value rapidly decreased after $30 \mathrm{~min}$ of submersion, until a minimum value reached at the end of $60 \mathrm{~min}$ of submersion. After this period there could be observed a recovery of this parameters until the end of the time course. Regarding the operational quantum yields, it could also be observed a decrease of its value in the submerged individuals, although in a smaller extent, reaching its minimum at the end of 60 min of time course with a recovery after this period. Considering the non-photochemical quenching (NPQ) of the air exposed individuals it could be observed that it presents a low and almost steady value along all the time course. On the other hand, in the submerged individuals the NPQ (Fig. 1E) increased from the beginning of the experiment until the end of $60 \mathrm{~min}$, after which it started to decrease towards minimum values at the end of $180 \mathrm{~min}$ of time course.

\subsection{Rapid light curves (RLCS)}

Observing the rETR at different light intensities (Fig. 2A-E), measured at different moments of the submersion experiment it was possible to assess a similar pattern to the previous reported for the PSII quantum yields. It could be observed that submerged individuals exhibited lower electron transport rates during the first 120 min of submersion at non-photoinibitory light intensities. After this period, a small increase in the rETR could be observed for all light intensities tested. This was reflected in the photosynthetic efficiency (Fig. 2F), where a significant increase could be detected in 

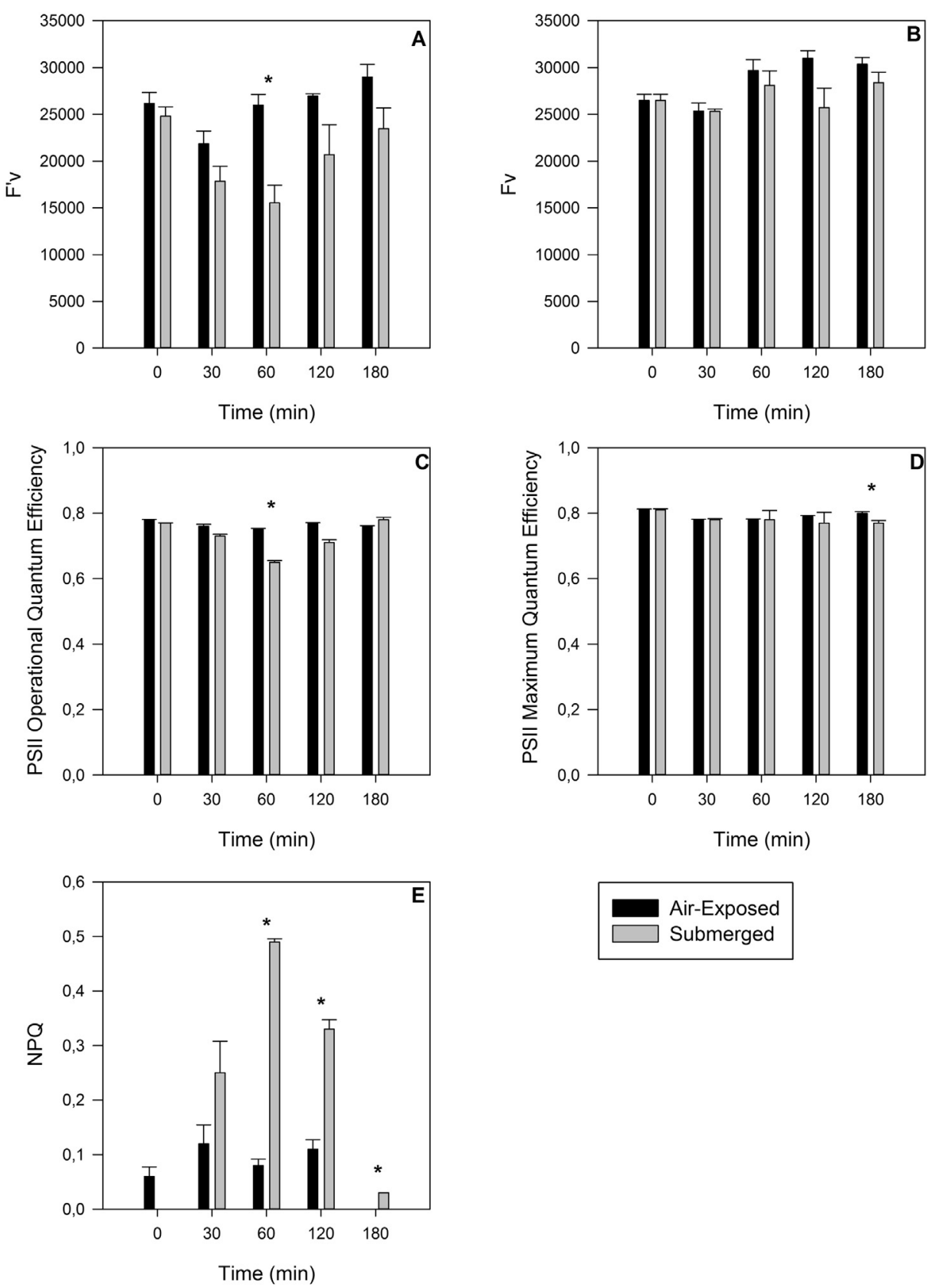

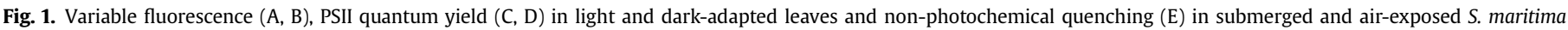
individuals (average \pm standard deviation, $n=5$; ${ }^{*} P<0.05$ ).

the plants submerged after 180 min, relatively to the air-exposed individuals.

\subsection{Kautsky curves, energy fluxes and driving forces}

A similar pattern could be observed by plotting Kautsky curves from the examined samples (Fig. 3). Until 120 min of submersion, the air-exposed individuals presented higher values of fluorescence both during the photochemical (O-J-I) and thermal (I-P) phases. This reflects changes in the energy fluxes involved in the light harvesting processes (Fig. 4). It was possible to observe that both the trapped and transported energy fluxes (Figs. $4 \mathrm{~B}$ and $\mathrm{C}$ ) were very similar among treatments and during $180 \mathrm{~min}$ of experiment. The major differences were observed at the end of $60 \mathrm{~min}$ in the absorbed (Fig. 4A) and dissipated energy fluxes (Fig. 4D), showing significant increases in the submerged individuals, especially in which concerns the dissipated energy flux. Overlooking the driving forces of each of the processes comprised within the photosynthetic light harvesting process, some interesting differences were notice (Fig. 5). Again it was possible to observe significant differences in the light energy absorption after $120 \mathrm{~min}$ (Fig. 5A), as reported above. Nevertheless, other differences could be found. Both the driving force for energy trapping (Fig. 5B) and for subsequent electron transport (Fig. 5C) showed marked decreases in the submerged individuals, more markedly after 120 min of submersion. This affects the whole force balance, reflected in the driving force for the overall photosynthetic process (Fig. 5D). Thus, the individuals subjected to submersion periods superior to $120 \mathrm{~min}$ 
$0 \min$

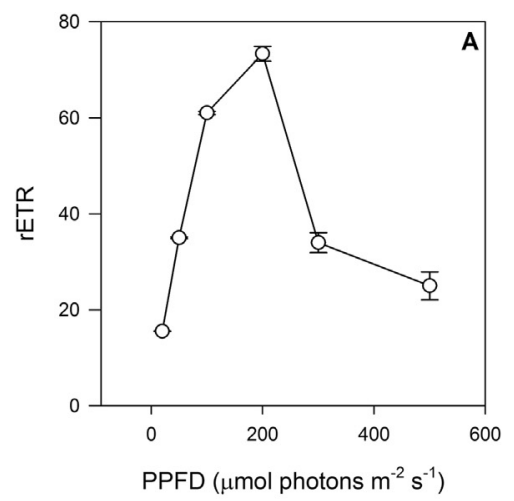

$60 \mathrm{~min}$

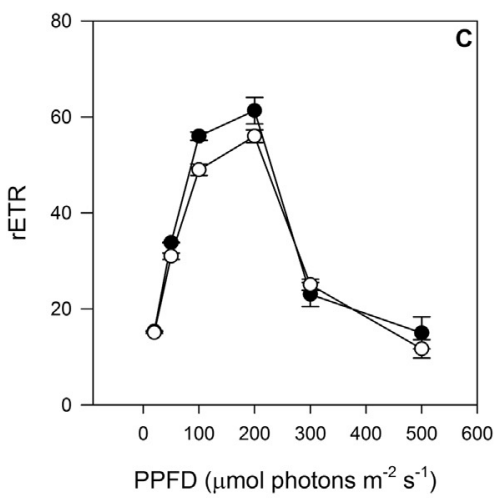

$180 \mathrm{~min}$

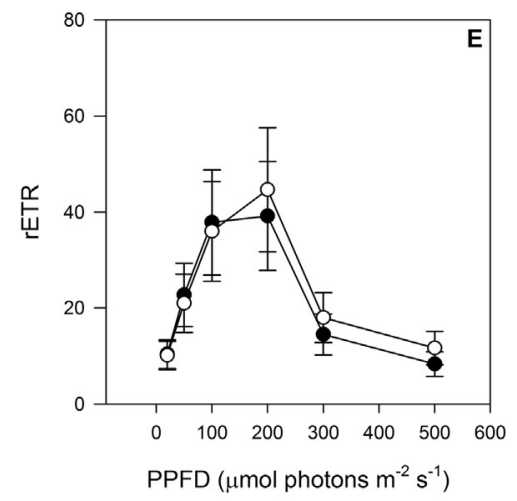

$30 \mathrm{~min}$

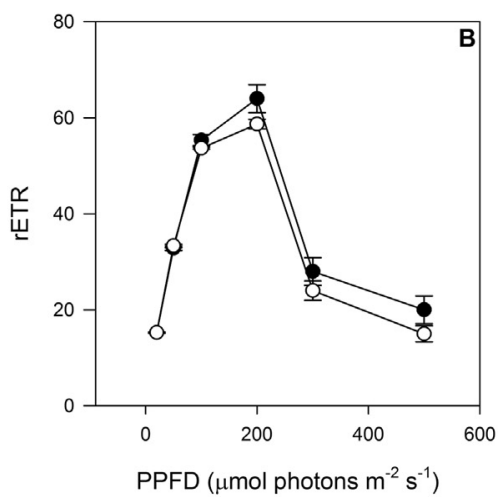

$120 \mathrm{~min}$
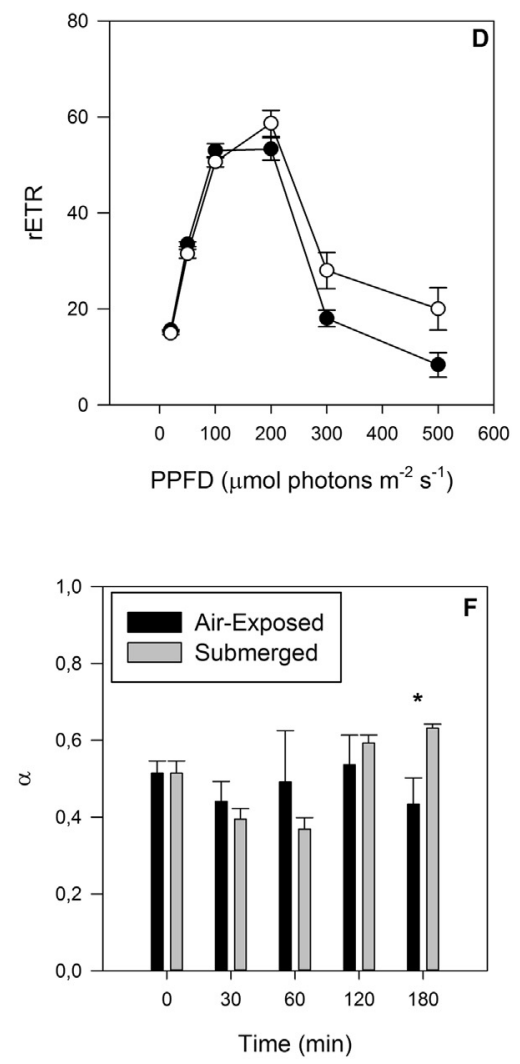

Air-exposed

Submerged

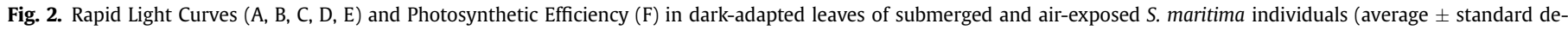
viation, $\left.n=5 ;{ }^{*} P<0.05\right)$.

showed significantly lower values of these parameters, while compared with the air-exposed individuals. Investigating deeper into the process that underlie the driving forces and energy fluxes, these processes are enlightened (Fig. 6). It was possible to observe that the maximum quantum yield of the primary photochemical processes occurring in the PSII, showed a significant decrease after 120 min of submersion (Fig. 6E). This was mostly due to a significant decrease in the transport efficiency of the captured electrons, both to the quinone system but also throughout the rest of the ETC (Figs. 6A and C). Concomitant with this and with the increase in the dissipated energy flux, also an increase in the quantum yield of the non-photochemical processes was observed in the submerged individuals and especially after $120 \mathrm{~min}$ of underwater treatment (Fig. 6B). Also, it could be notice that during the first hour of submersion, the individuals exhibited a decrease in the area above the Kautsky curve (Fig. 6D), directly related to the size of the acceptor pool of the PSII, including quinones and plastoquinone. Regarding the connectivity between the two units of the PSII, here evaluated by the grouping probability (Fig. 6F), no significant changes in the connectivity between photosynthetic units were found at this level. 


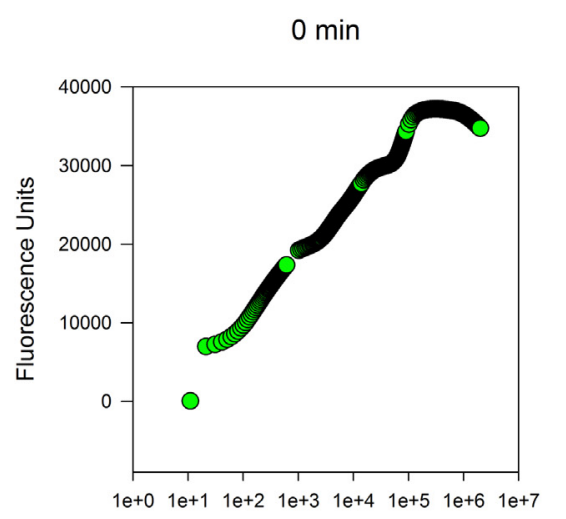

$\log$ Time $(\mu s)$

$60 \mathrm{~min}$

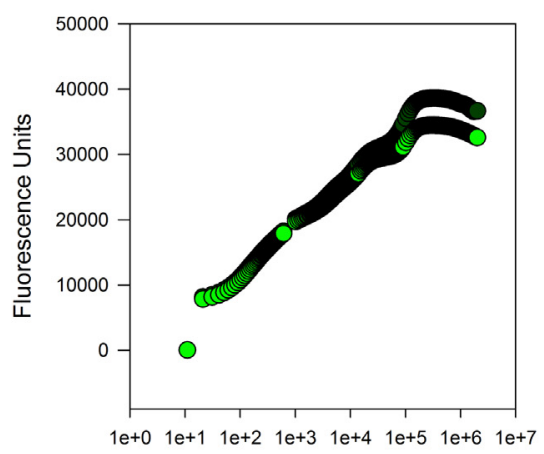

$\log$ Time $(\mu \mathrm{s})$

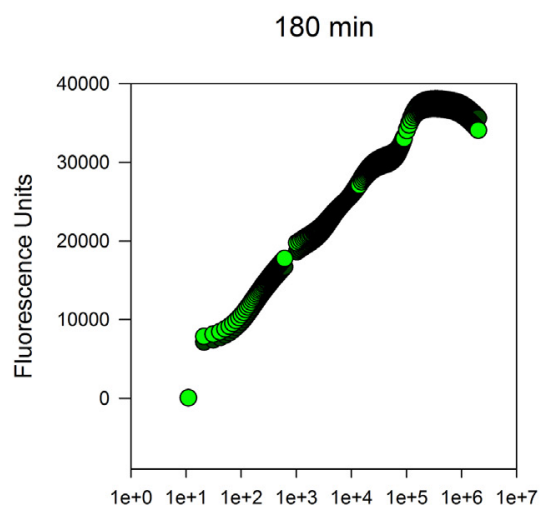

log Time $(\mu s)$
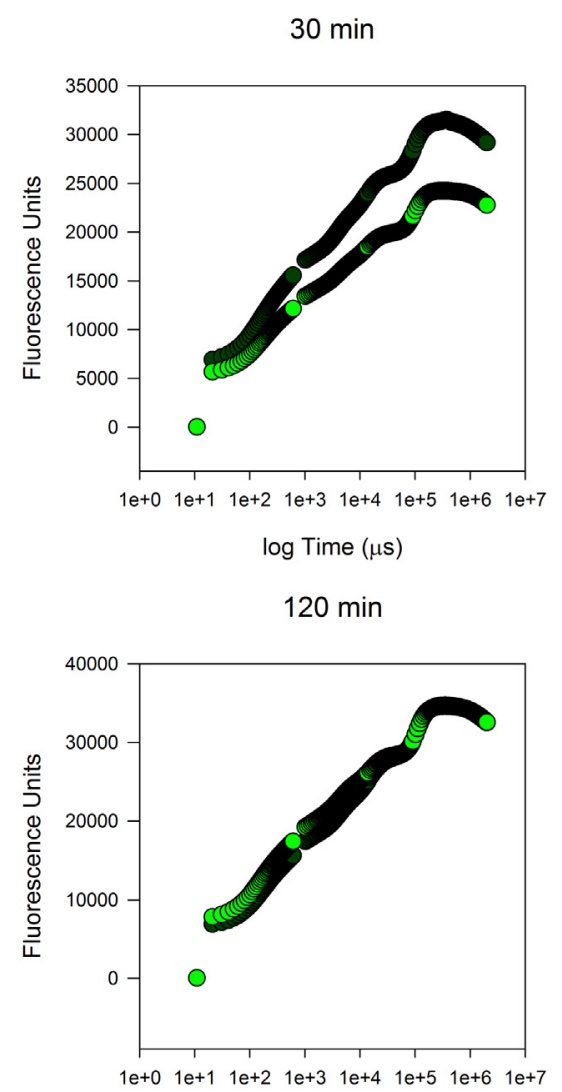

$\log$ Time ( $\mu \mathrm{s})$

Fig. 3. Average values of the Kautsky curves in dark-adapted leaves of submerged and air-exposed $S$. maritima individuals (Average values, $n=5$ ).

\subsection{Oxidative stress biomarkers}

Overall it is possible to observe that superoxide dismutase activity was the most active form of enzymatic counteractive measures (Fig. 7B). During the first 30-60 min of submersion there was a significant increase in the activity of all anti-oxidant enzymes (Fig. 7A-D). After this period there is an evident decrease in these activities, reaching values near the observed in the air-exposed individuals at the end of 180 min of submersion.

\section{Discussion}

Considering the present predictions of sea level rise and especially for coastal systems (IPCC, 2002), it is possible that newer or less accreted marshes see their submersion periods increased. During high tide, the lower marsh areas stay flooded for short periods (approximately $2 \mathrm{~h}$ according to Serôdio and Catarino, 2000). With increased sea level heights not only the high tide duration but also the frequency of high low tides are likely to increase, exposing the lower marsh vegetation to increased submersion periods. These changes in the hydrological environment of the species will inevitably impact their photosynthetic physiology. According to recent studies, S. maritima will be negatively affected with sea level rise, decreasing their biomass and thus its coverage area (Valentim et al., 2013). This way it becomes important to understand the photobiological causes underlying this projected drawback in the S. maritima populations. 

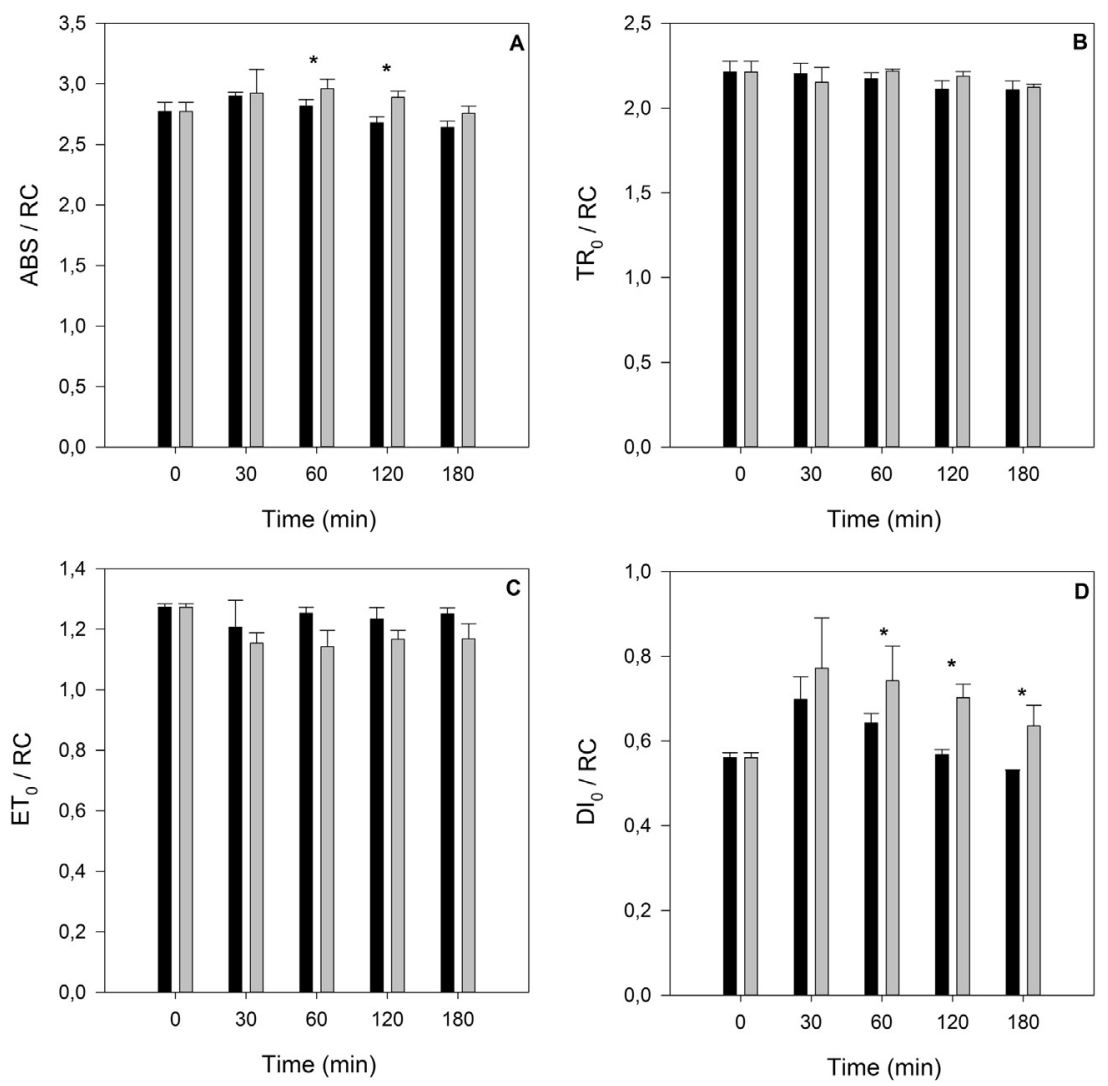

Air-exposed
Submerged

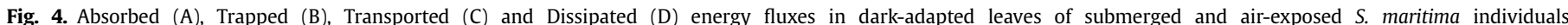
(average \pm standard deviation, $n=5 ;{ }^{*} P<0.05$ ).

As observed in previous studies focussing S. maritima communities (Silva et al., 2005) although the manly terrestrial characteristics of this species, there was no inhibition of photosynthetic activity in submerged individuals. These authors found that comparing both communities (submerged and air-exposed), in the terrestrial environment $S$. maritima scavenges about four times more carbon than during submersion (Silva et al., 2005).

The shape of the OJIP transient curve is very sensitive to environmental stresses (Zhang and Gao, 1999; Calatayud and Barreno, 2001; Strasser and Tsimilli-Michael, 2001; Sayed, 2003; van Heerden et al., 2003; Govindachary et al., 2004). During the first hours of submersion the shape of the OJIP transient suffered some alterations resulting in a pronounced decreased on the variable fluorescence of all phases. The rapid $\mathrm{O}$ to $\mathrm{J}$ rise is a phase controlled by photochemical processes, while J to I is a strictly thermal phase (Schreiber and Neubauer, 1987). The release of fluorescence from this phase is controlled by the reactions occurring in the donor side of the PSII. Any abiotic stress that disturbs the structure and function of the oxygen evolving complexes (OECs), affects the rate of oxygen evolution and thus increases the release of fluorescence quenching in the J-I phase (Panda et al., 2006). On the other hand, the rise in the O-J phase is due to the PSII quinone pool reduction net photochemical (Prakash et al., 2003). Comparing both the donor (J-I) with the acceptor (O-J) PSII sides, the first was more severely affected during the first hours of submersion, due to the inactivation of the OEC and consequent impairment of the ETC (Panda et al., 2006). There could also be verified a reduction in the area above the transient curve, directly related to the size of the quinone pool in the acceptor side of the PSII (Strasser et al., 1995; Joliot and Joliot, 2002). This was more evident also during the first hour of submersion. This reduction is in agreement with the overall deleterious effect of submersion on the PSII, as already was described in other plant species (Panda et al., 2006; MateosNaranjo et al., 2007). Inevitably, this decrease of $F_{M}$ in the transient OJIP affects the $F_{v} / F_{M}$ relationship and thus the PSII quantum yields, as could also be verified at the end of $1 \mathrm{~h}$ of submersion. This reinforces the previous findings, pointing out to a reduction in the PSII capacity to reduce the primary acceptor, $Q_{A}$. Although this apparent damage in the donor side of the PSII, this was also verified during the first hour of submersion, not affecting substantially the electron transport per reaction active centre $\left(\mathrm{ET}_{0} / \mathrm{RC}\right)$. This indicates that the reduction in the electron flow is accompanied by a proportional increase in the number of active reaction centres $(\mathrm{ABS} / \mathrm{RC})$, to overcome this reduction in the electron transport. The increase in the $A B S / R C$ is normally associated to low light levels or significant temperature changes, functioning as a heat radiator, protecting the plant against high temperature and light intensities (Strasser et al., 2004; Panda et al., 2008). Although the experimental conditions maintained the temperature constant in both treatments, there were differences in the light environment between submerged and non-submerged plants, as normally happens in real-marsh conditions during high tide. This lead to an increase of the number of active reaction centres in order to harvest higher amounts of light. Interesting to notice was the fact that this increase 

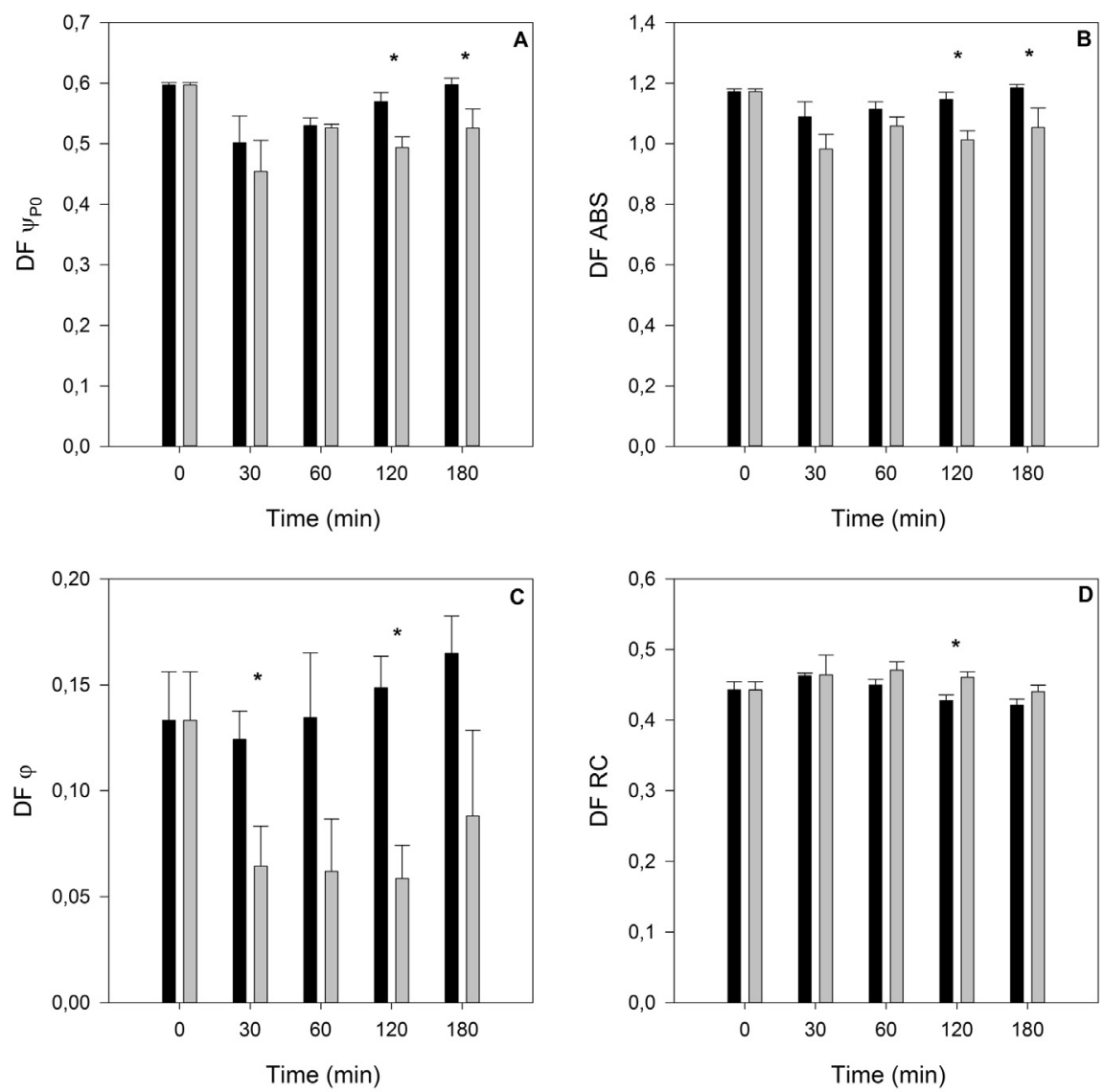

Air-exposed Submerged

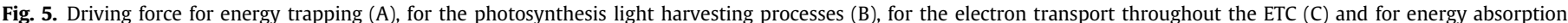
throughout the PSII (D) in dark-adapted leaves of submerged and air-exposed S. maritima individuals (average \pm standard deviation, $n=5$; ${ }^{*} P<0.05$ ).

happened at the end of the first hour of submersion, simultaneously with the reduction in the electron transport. From hereafter almost all the parameters showed a recovery, pointing out to a timestamp in the adaptation ability of $S$. maritima to submersion. This increase in active centres, without proportional increase in electron transport efficiency, leads to an accumulation of excessive energy that according to our data, suffered impairment in its transport along the ETC, and thus had to be dissipated. Panda et al. (2006) also found a similar mechanism with consequent excessive energy release in the form of heat dissipation $\left(\mathrm{DI}_{0} / \mathrm{RC}\right)$, increasing the quantum yield of the non-photochemical reaction, counteracting the effects of submergence in rice plants. The OJIP-test also provided means to calculate the overall $P_{G}$ or connectivity between PSII antennae. This parameter accounts for all the energetic communication pathways between neighbour PSII antennae (Strasser and Stirbet, 2001; Panda et al., 2006). On the contrary to what could be observed in other terrestrial plants, there was no loss of connectivity between the antennae of the PSII units during submersion, indicating an improved survival strategy for underwater conditions (Panda et al., 2006).

The accumulation of energy even with efficient dissipative mechanisms leads to the generation of reactive oxygen species (ROS) that by itself can also damage the PSII and the cellular components of the ETC (Duarte et al., 2013b). To counteract this damaging effects of ROS, the cell has a machinery mainly composed by enzymatic mechanisms, in order to degrade these molecules and prevent cellular damage, namely at the photosynthetic apparatus level. Similarly to the observed for the photochemical data, also at the biochemical level these mechanisms follow a similar trend. The majority of the analysed anti-oxidant enzymes showed peaks of activity in the period comprised between 30 and 60 min of submersion. This is in agreement to what as found for the photochemical data. During this period there was higher accumulation of reducing power that had to be dissipated, and thus higher amounts of ROS were generated. The efficient activation of these enzymes points out towards an efficient mechanism, not only for dissipation of the excessive reducing power by the non-photochemical mechanisms, but also for detoxification of the dangerous products resultant of the accumulation of excessive energy. This was also verified in other halophytic species during stress-induced photochemical impairment as a protective measure from the excessive reducing power, even under efficient dissipation (Duarte et al., 2013b).

Overall a positive feedback to submersion can be observed in S. maritima individuals after $60 \mathrm{~min}$ of submergence, with increasing values of the processes associated to the photochemical yield and electronic transport and decrease in the nonphotochemical processes, like energy dissipation. This points out to a photochemical plasticity in this species towards submersion, as shown in other aquatic species like seagrasses (Silva et al., 2005). 

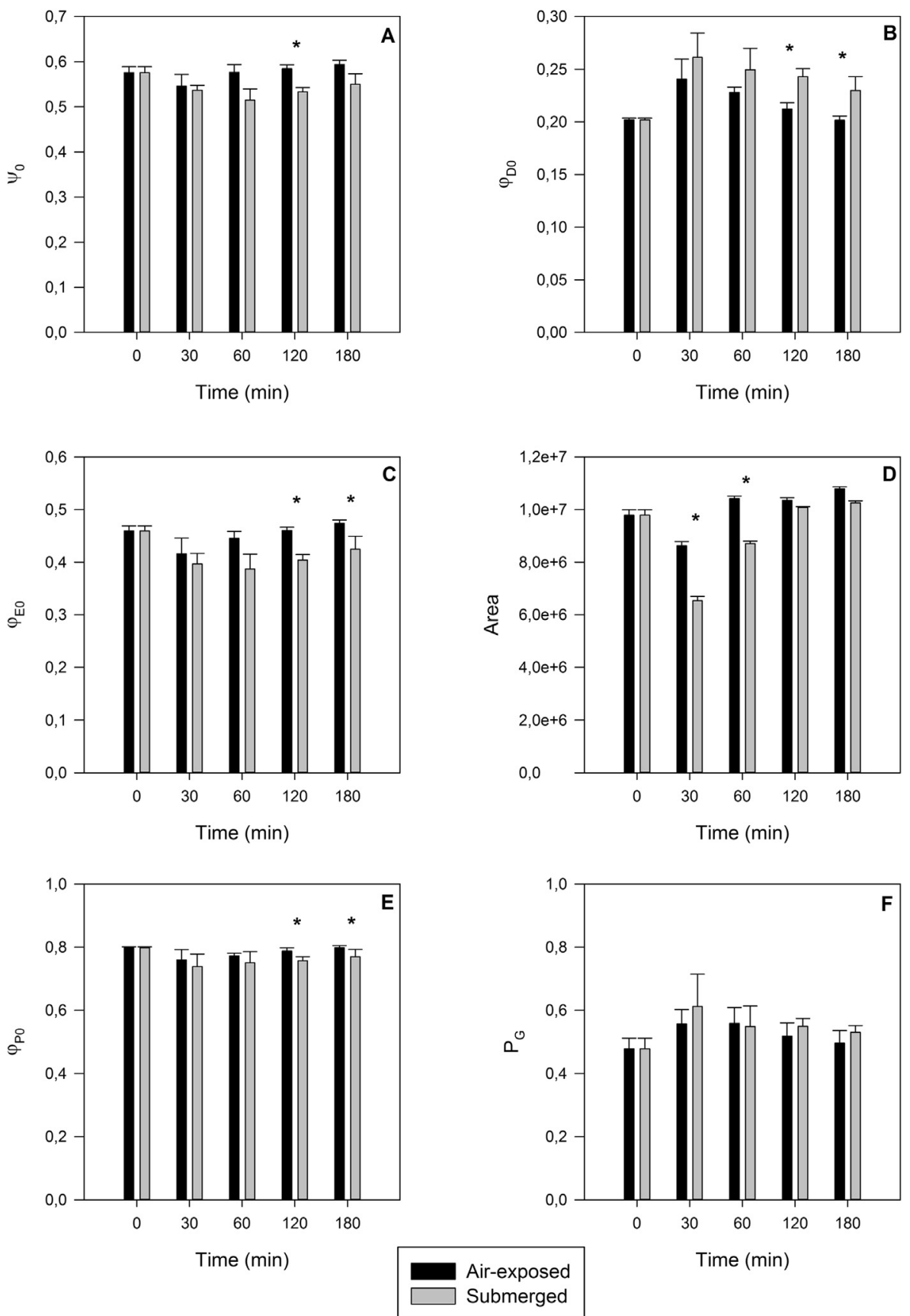

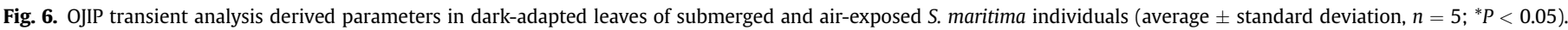

Moreover, the adaptation to the underwater environment appears to be dependent on the duration of the stimulus (submergence). All these biophysical characteristics, confirmed by the biochemical insights provided by the levels of anti-oxidant enzymes, point out to the existence of capable mechanisms triggered in prolonged submersion periods, like the ones expected according sea level rise projections.

\section{Conclusion}

Diurnal tidal flooding imposes to the halophyte community an underwater environment with conditions very different from the terrestrial ones. The predicted sea level rise increase will have consequences not only on the height of the tidal inundation but also in the duration of the high tides. Thus, becomes important to consider the physiology of each species, and the consequences of their adaptation capacity in terms of ecosystem, towards a changing environment, especially in the case of the species inhabiting the lower marsh, like $S$. maritima. This species presents a high adaptation capacity to submersion. Although after short periods of submersion an evident reduction of primary PSII photochemistry could be observed mainly due to incapacity to deal with the absorbed light, after prolonged periods it evidences effective mechanisms to dissipate the excessive energy and for detoxification of the accumulated ROS, increasing the photosynthetic efficiency. All these aspects point out to an evident photochemical 

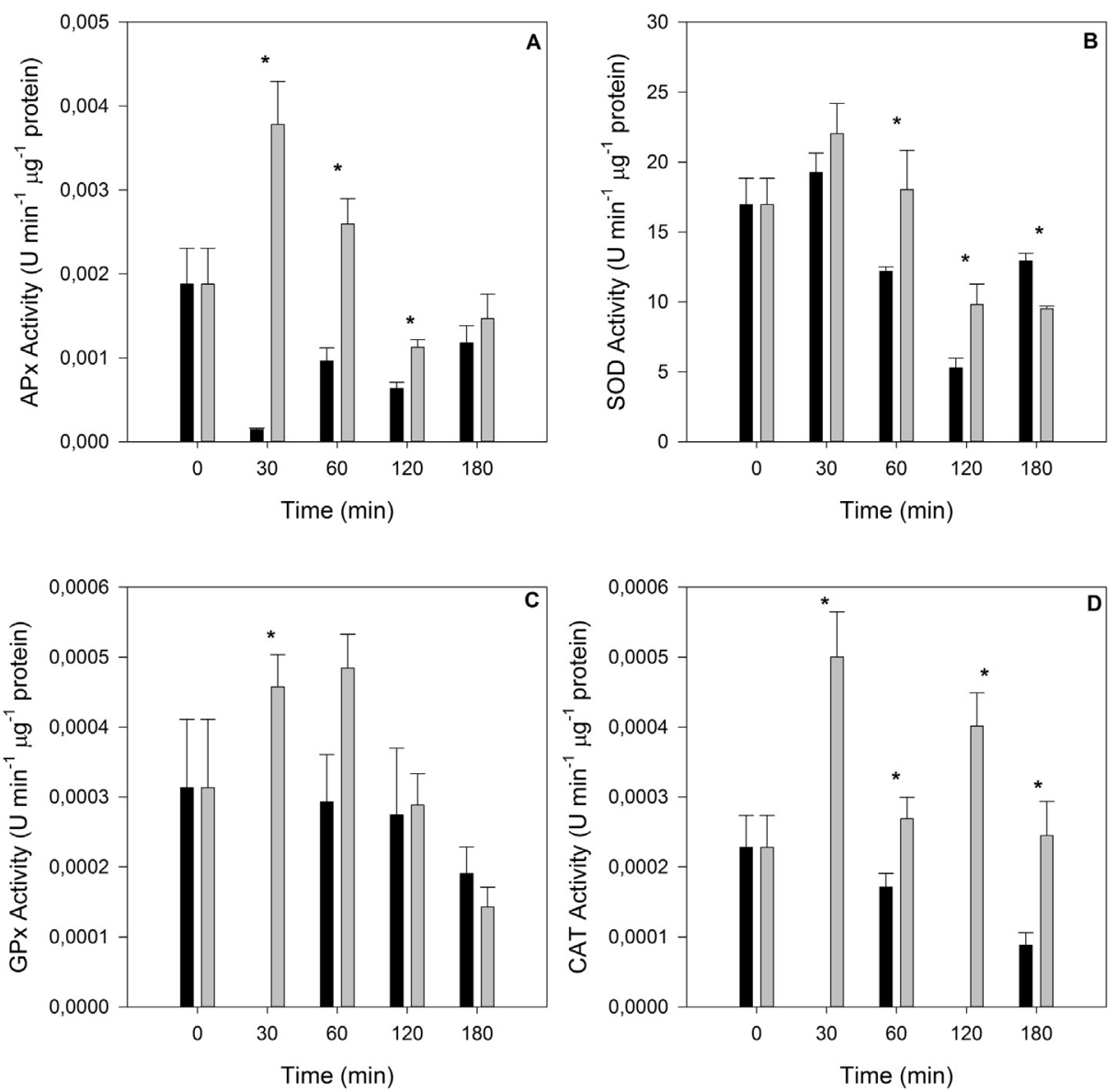

Air-exposed Submerged

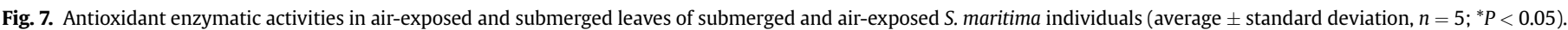

plasticity of this species towards prolonged submersion periods like those expected under sea level rise, allowing it to maintain its photosynthetic activity even during prolonged submersion periods, and thus surviving the near future climate change scenarios.

\section{Contributions}

In the present work all the authors were involved according to their area of expertise. Dr. Bernardo Duarte was responsible of the biophysical and photochemical analysis and Dr. Dinis Santos of the anti-oxidant enzymatic assays. Prof. Isabel Caçador and Prof. João Carlos Marques were responsible for the supervision of the work and final corrections and suggestions in the data interpretation.

\section{Acknowledgements}

The authors would like to thank to the " Fundação para a Ciência e Tecnologia (FCT)" for funding the research in the Centre of Oceanography (CO) throughout the project PEst-OE/MAR/UI0199/ 2011, the Institute of Marine Research (IMAR) throughout the project PEst-C/MAR/UI0284/2011 and this specific work throughout the ECOSAM project (PTDC/AAC-CLI/104085/2008). B. Duarte investigation was supported by FCT throughout a PhD grant (SFRH/BD/75951/2011).

\section{References}

Armstrong, W., 1972. A re-examination of the functional significance of aerenchyma. Physiol. Plantarum. 27, 173-177.

Armstrong, W., 1979. Aeration in higher plants. Adv. Bot. Res. 7, 225-332.

Armstrong, W. Wright, E.J., Lythe, S., Gaynard, T.J., 1985. Plant zonation and the effects of the spring-neap tidal cycle on soil aeration in a Humber salt marsh. J. Ecol. 73, 323-339.

Bailey-Serres, J., Voesenek, L., 2008. Flooding stress: acclimatations and genetic diversity. Annu, Rev. Plant Biol. 59, 313-339.

Beer, S., Ilan, M., Eshel, A., Weil, A., Brickner, I., 1998a. The use of pulse amplitude modulated (PAM) fluorometry for in situ measurements of photosynthesis in two Red Sea Faviid corals. Mar. Biol. 131, 607-612.

Beer, S., Vilenkin, B., Weil, A., Veste, M., Susel, L., Eshel, A., 1998b. Measuring photosynthesis in seagrasses by pulse amplitude modulated (PAM) fluorometry. Mar. Ecol. Prog. Ser. 174, 293-300.

Bergmeyer, H.U., Gawehn, K., Grassl, M., 1974. Enzymes as biochemical reagents. In: Bergmeyer, H.U. (Ed.), Methods in Enzymatic Analysis. Academic press, New York.

Bertness, M.D., 1991. Zonation of Spartina patens and Spartina alterniflora in New England salt marsh. Ecology 72, 138-148.

Bradford, M., 1976. A rapid and sensitive method for the quantification of microgram quantities of protein utilizing the principle of protein-dye-binding. Anal. Biochem. 72, 248-254.

Burdick, D.M., Mendelssohn, I.A., 1987. Waterlogging responses in dune, swale and marsh populations of Spartina patens under field conditions. Oecologia 74, 321-329.

Caçador, I., Caetano, M., Duarte, B., Vale, C., 2009. Stock and losses of trace metals from salt marsh plants. Mar. Environ. Res. 67, 75-82.

Caçador, I., Tibério, S., Cabral, H., 2007. Species zonation in Corroios salt marsh in the Tagus estuary (Portugal) and its dynamics in the past fifty years. Hydrobiologia 587, 205-211. 
Calatayud, A., Barreno, E., 2001. Chlorophyll a fluorescence, antioxidant enzymes and lipid peroxidation in tomato in response to ozone and benomyl. Environ. Pollut. 115, 283-289.

Colmer, T., Voesenek, L., 2009. Flooding tolerance: suites of plant traits in variable environments. Funct. Plant Biol. 36, 665-681.

Colmer, T.D., Flowers, T.J., 2008. Flooding tolerance in halophytes. New. Phytol. 179, 964-974.

Duarte, B., Couto, T., Freitas, J., Valentim, J., Silva, H., Marques, J.C., Caçador, I., 2013a. Abiotic modulation of Spartina maritima photosynthetic ecotypic variations in different latitudinal populations. Estuar. Coast. Shelf Sci. 130, 127-137.

Duarte, B., Raposo, P., Caçador, I., 2009. Spartina maritima (cordgrass) rhizosediment extracellular enzymatic activity and its role on organic matter decomposition and metal speciation processes. Mar. Ecol. 30, 65-73.

Duarte, B., Santos, D., Marques, J.C., Caçador, I., 2013b. Ecophysiological adaptations of two halophytes to salt stress: photosynthesis, PS II photochemistry and antioxidant feedback - implications for resilience in climate change. Plant Physiol. Biochem. 67, 178-188.

Egan, T.P., Ungar, I.A., 2000. Mortality of the salt marsh species Salicornia europaea and Atriplex prostrata (Chenopodiaceae) in response to inundation. Ohio J. Sci. 100, 24-27.

Flowers, T.J., Colmer, T.D., 2008. Salinity tolerance in halophytes. New. Phytol. 179, 945-963.

Genty, B., Briantais, J.-M., Baker, N., 1989. The relationship between the quantum yield of photosynthetic electron transport and quenching of chlorophyll fluorescence. Biochim. Biophys. Acta 990, 87-92.

Govindachary, S., Bukhov, N.G., Joly, D., Carpentier, R., 2004. Photosystem II inhibition by moderate light under low temperature in intact leaves of chillingsensitive and - tolerant plants. Physiol. Plantarum. 121, 322-333.

Hubbard, J.C.E., 1969. Light in relation to tidal immersion and growth of Spartina townsendii (sl). J. Ecol. 57, 795-804.

IPCC, 2002. Climate change and biodiversity. IPCC Technical Paper V. In: Contribution of the Working Group II to the to the Fourth Assessment Report of the Intergovernmenal Panel on Climate Change.

Iversen, J.S., 1949. Determinations of the specific gravity of the roots of swamp, meadow and dry-soil plants. Oikos 1, 1-5.

Joliot, P., Joliot, A., 2002. Cyclic electron transport in plant leaf. PNAS 99, 1020910214

Marchant, C., Goodman, P., 1969. Spartina maritima (Curtis) Fernald. J. Ecol. 57, 287-291.

Marklund, S., Marklund, G., 1974. Involvement of superoxide anion radical in the autoxidation of pyrogallol and a convenient assay for superoxide dismutase. Eur. J. Biochem. 47, 464-469.

Marshall, H.J., Geider, R.J., Flynn, K.J., 2000. A mechanistic model of photoinhibition. New Phytol. 145, 347-359.

Mateos-Naranjo, E., Rendondo-Gómez, S., Silva, J., Santos, R., Figueroa, E., 2007. Effect of prolonged flooding on the invader Spartina densiflora brong. J. Aquat. Plant Manag. 45, 121-123.

Panda, D., Rao, D.N., Sharma, S.G., Strasser, R.J., Sarkar, R.K., 2006. Submergence effects on rice genotypes during seedling stage: probing of submergence driven changes of photosystem 2 by chlorophyll a fluorescence induction O-J-I-P transients. Photosynthetica 44, 69-75.

Panda, D., Sharma, S.G., Sarkar, R.K., 2008. Chlorophyll fluorescence parameters, $\mathrm{CO}_{2}$ photosynthetic rate and regeneration capacity as a result of complete submergence and subsequent re-emergence in rice (Oryza sativa L.). Aquat. Bot. 88, 127-133.

Pedersen, O., Colmer, T., 2006. Oxygen dynamics during submergence in the halophytic stem succulent Halosarcia pergranulata. Plant Cell. Environ. 29, 1389-1399.

Platt, T., Gallegos, C.L., Harrison, W.G., 1980. Photoinhibition of photosynthesis in natural assemblages of marine phytoplankton. J. Mar. Res. 38, 687-701.

Prakash, J.S.S., Srivastava, A., Strasser, R.J., Mohanty, P., 2003. Senescence-induced alternation in the photosystem II functions of Cucumis sativus cotyledons: probing of senescence driven alternation of photosystem II by chlorophyll a fluorescence induction O-J-I-P transients. Indian J. Biochem. Biophys. 40, 160-168.
Reed, D.J., 2002. Sea-level rise and coastal marsh sustainability: geological and ecological factors in the Mississippi delta plain. Geomorphology 48, 233-243.

Runcie, J.W., Durako, M.J., 2004. Among-shoot variability and leaf-specific absorbance characteristics affect diel estimates of in situ electron transport of Posidonia australis. Aquat. Bot. 80, 209-220.

Sand-Jensen, K., 1989. Environmental variables and their effect on photosynthesis of aquatic plant communities. General features to aquatic photosynthesis. Aquat. Bot. 34, 5-25.

Sayed, O.H., 2003. Chlorophyll fluorescence as a tool in cereal crop research. Photosynthetica $41,321-330$.

Schreiber, U., Neubauer, C., 1987. The polyphasic rise of chlorophyll fluorescence upon onset of strong continuous illumination: partial control by the photosystem II donor side and possible ways of interpretation. Z. für Naturforsch. 42c $1255-1264$.

Serôdio, J., Catarino, F., 2000. Modelling the primary production of intertidal microphytobenthos: time scales of variability and effects of migratory rhythms. Mar. Ecol. Prog. Ser. 192, 13-30.

Setter, T.L., Waters, I., 2003. Review of prospects for germplasm improvement for waterlogging tolerance in wheat, barley and oats. Plant Soil. 253, 1-34.

Sifton, H.B., 1945. Air-space tissue in plants. Bot. Rev. 11, 108-143.

Silva, J., Santos, R., Calleja, M.L., Duarte, C.M., 2005. Submerged versus air-exposed intertidal macrophyte productivity: from physiological to community-level assessments. J. Exp. Mar. Biol. Ecol. 317, 87-95.

Smith, F., Walker, N., 1980. Photosynthesis by aquatic plants: effects of unstirred layers in relation to assimilation of $\mathrm{CO}_{2}$ and $\mathrm{HCO}_{3}^{-}$and to carbon isotopic discrimination. New. Phytol. 86, 245-259.

Strasser, R.J., Stirbet, A.D., 2001. Estimation of the energetic connectivity of PS II centres in plants using the fluorescence rise $\mathrm{O}-\mathrm{J}-\mathrm{I}-\mathrm{P}$. Fitting of experimental data to three different PS II models. Math. Comput. Simul. 56, 451-461.

Strasser, R.J., Tsimilli-Michael, M., 2001. Stress in plants, from daily rhythm to globa changes, detected and quantified by the JIP test. Chim. Nouv. (SRC) 75, 33213326.

Strasser, R.J., Srivastava, A., Govindjee, 1995. Polyphasic chlorophyll a fluorescence transient in plants and cyanobacteria. Photochem. Photobiol, 61, 32-42.

Strasser, R.J., Tsimilli-Michael, M., Srisvastava, A., 2004. Analysis of the chlorophyll-a fluorescence transiente. In: Papageorgiou, G.C., Govindjee (Eds.), Advances in Photosynthesis and Respiration. Springer, Berlin, pp. 321-362.

Teranishi, Y. Tanaka, A., Osumi, M., Fukui, S., 1974. Catalase activities of hydrocarbon-utilizing Candida yeast. Agric. Biol. Chem. 38, 1213-1220.

Tiryakioglu, M., Eker, S., Ozkutlu, F., Husted, S., Cakmak, I., 2006. Antioxidant defense system and cadmium uptake in barley genotypes differing in cadmium tolerance. J. Trace Elem. Med. Biol. 20, 181-189.

Valentim, J.M., Vaz, N., Silva, H., Duarte, B., Caçador, I., Dias, J.M., 2013. Tagus estuary and Ria de Aveiro Salt marsh dynamics and the impact of sea level rise. Estuar. Coast. Shelf Sci. 130, 138-151.

van Heerden, P.D.R., Tsimilli-Michael, M., Krüger, G.H., Strasser, R.J., 2003. Dark chilling effects on soybean genotypes during vegetative development; parallel studies of $\mathrm{CO}_{2}$ assimilation, chlorophyll a fluorescence kinetics O-J-I-P and nitrogen fixation. Physiol. Plantarum. 117, 476-491.

Voesenek, L., Rijnders, J., Peeters, A., van de Steeg, H., Kroon, H., 2004. Plant hormones regulate fast shoot elongation under water: from genes to communities. Ecology 85, 16-27.

Winkel, A., Colmer, T.D., Pedersen, O., 2011. Leaf gas films of Spartina anglica enhance rhizome and root oxygen during tidal submergence. Plant Cell. Environ. 34, 2083-2092.

Zhang, S., Gao, R., 1999. Diurnal changes of gas exchange, chlorophyll fluorescence and stomatal aperture of hybrid poplar clones subjected to midday light stress. Photosynthetica 37, 559-571.

Zhu, X.G., Govindjee, Baker, N.R., Sturler, E.D., Ort, D.R., Long, S.P., 2005. Chlorophyl a fluorescence induction kinetics in leaves predicted from a model describing each discrete step of excitation energy and electron transfer associated with Photosystem II. Planta 223, 114-133. 